\title{
Liberdade na obra de F.A Hayek e John Rawls
}

\author{
Alexandre de Freitas Faisst ${ }^{I}$ (1) 0000-0003-0065-6627 \\ Universidade Estadual de Ponta Grossa - UEPG - Ponta Grossa - Paraná - Brasil
}

Resumo: O presente artigo compara o conceito de liberdade nas obras de Friedrich Hayek e John Rawls. O objetivo deste artigo é analisar comparativamente tais conceitos, com vista no âmbito político jurídico, assim como as suas concepções de liberalismo. Partindo de elementos comuns, analisamos o conceito de liberdade em Hayek, conforme as obras O caminho da servidão (1945) e Constitution of Liberty (1960), e o conceito enunciado por Rawls, conforme as obras Uma teoria de justiça (1971) e Liberalismo Político (1993). Concluímos que, embora ambos estejam dentro da ampla tradição do liberalismo, divergem em pontos importantes, o que aproxima Rawls da democracia deliberativa e Hayek do libertarianismo.

Palavras-chave: Hayek, Rawls, Liberdade, Filosofia Política. 


\title{
Libertad en la obra de F.A Hayek y John Rawls
}

\begin{abstract}
This article compares the concept of freedom in the works of Friedrich Hayek and John Rawls. Its purpose is to comparatively analyze such concepts with a view of the political-legal scope and their conceptions of liberalism. Based on similar elements, Hayek's idea of freedom is analyzed according to the works Road to Serfdom (1945) and Constitution of Liberty (1960), and Rawls' from the books A Theory of Justice (1971) and Political Liberalism (1993). Although both are within the broad tradition of liberalism, they diverge on many points, bringing Rawls closer to deliberative democracy and Hayek to libertarianism.
\end{abstract}

Keywords: Hayek, Rawls, Freedom, Political Philosophy.

\section{Freedom in the work of F.A Hayek and John Rawls}

Resumen: El presente trabajo hace una comparación entre los conceptos de libertad en las obras de Friedrich Hayek y John Rawls. El propósito del artículo es analizar tales conceptos con la intención de ver el alcance político jurídico, así como sus concepciones de liberalismo. A partir de elementos comunes, se analiza el concepto de libertad en Hayek, de acuerdo con las obras Camino de Servidumbre (1945) y Constitution of Liberty (1960), y el concepto enunciado por Rawls a partir de las obras: Una Teoría de Justicia (1971) y El Liberalismo Político (1993). Se ha concluido que, aunque ambos quedan dentro de una amplia tradición del liberalismo, divergen en puntos importantes, lo que acerca Rawls a la democracia deliberativa y Hayek al libertarismo.

Palabras clave: Hayek, Rawls, Libertad, Filosofía Política. 


\section{Introdução}

O liberalismo é uma filosofia política e econômica que possui como premissas gerais a autonomia individual, a igualdade de oportunidades e a proteção dos direitos individuais. De acordo com Merquior (1986), o liberalismo não é uma filosofia unitária, mas é constituída por diversos liberalismos que adotam a liberdade como o centro da sua linha de pensamento.

Entretanto, essa pluralidade de liberalismos é constantemente deixada de lado no debate público brasileiro sendo frequentemente apresentado em sua concepção unitária, de maneira caricata e desprovida do seu significado original. Para fazer um esclarecimento sobre a verdadeira proposta do liberalismo, esse artigo faz a comparação entre o conceito de liberdade entre dois importantes autores liberais do século XX: Friedrich Hayek e John Rawls.

Friedrich Hayek (1899-1992) foi um economista e filósofo de origem austríaca, mas que construiu a maior parte de sua carreira intelectual na Inglaterra. Iniciou a sua carreira na área das ciências econômicas, a qual lhe rendeu um Nobel de Economia em 1974, porém, também, dedicou boa parte de seus estudos à história das ideias políticas e da filosofia social. É um notório defensor da liberdade e é reconhecido por Merquior (1986) como o responsável pelo renascimento do debate acerca da importância da liberdade econômica, a qual havia sido deixada de lado após a Segunda Guerra Mundial.

John Rawls (1921-2002), outro notório filósofo da tradição liberal, ex-combatente da Segunda Guerra Mundial e professor de Harvard, onde lecionou por quase quarenta anos. Iniciou sua carreira nos estudos sobre teologia, contudo desenvolveu a maior parte do seu trabalho na área da filosofia moral e filosofia do direito. Foi um expoente do liberalismo igualitário, sendo conhecido principalmente pela sua ideia de justiça como equidade, a qual descreve uma sociedade de cidadãos livres com direitos básicos iguais e cooperando dentro de um sistema econômico igualitário.

Ainda que tais estudiosos reconheçam a importância da liberdade e estejam inseridos na tradição liberal, ambos possuem profundas diferenças no desenvolvimento de suas ideias morais e políticas. Sendo assim, é necessária a discussão dessas questões para entender a importância do liberalismo na atualidade. Esse artigo busca esclarecer as diferenças conceituais sobre liberdade, apresentadas por cada autor através do método comparativo. Para tal, faz uso da pesquisa de natureza bibliográfica, analisando as obras O Caminho da Servidão (1945) e Constitution of Liberty (1960) de Friedrich Hayek, e as obras Uma Teoria da Justiça (1971) e Liberalismo Político (1993) de John Rawls.

O texto faz uso do método de análise comparativa de materiais bibliográficos. $\mathrm{Na}$ primeira parte do texto, serão analisadas as inspirações ideológicas e ideias fundamentais para entender a filosofia da liberdade de cada autor já mencionado anteriormente. Em seguida, será analisado e comparado o conceito de liberdade entre ambos e, por fim, serão analisados conceitos e ideias adjacentes ao termo liberdade, para compreender de maneira mais ampla a filosofia de Hayek e Rawls. 


\section{Precedentes Ideológicos}

A publicação do livro O caminho da Servidão, de Friedrich Hayek, em 1944, durante a Segunda Guerra Mundial, promoveu uma série de debates e discussões acerca de conceitos como democracia, planejamento econômico e liberdade. O livro dirigia-se especialmente à classe dos socialistas britânicos, no entanto, fez mais sucesso na antiga colônia britânica, os Estados Unidos.

Os Estados Unidos ainda não haviam experienciado tentativas de planejamento central e restrições de liberdade que impactariam na economia e a publicação do livro coincidiu com o momento em que tais assuntos entraram em pauta. Enquanto, a ideia do planejamento havia se tornado antiquada para boa parte dos europeus, ainda existia nos Estados Unidos, como uma esperança radiosa de um mundo melhor (HAYEK, 1944).

Os anos subsequentes da publicação do livro foram seguidos por estudos cada vez mais aprofundados sobre os estados totalitários. Hayek começou a receber cada vez mais respostas sobre seu primeiro livro, as quais o motivaram a se dedicar de maneira integral ao campo da filosofia política e da filosofia moral. O resultado viria 16 anos depois, com o lançamento da obra The Constitution of Liberty, em 1960.

Nesta obra, Hayek (1960) expõe as diferentes formas de liberdade de uma maneira mais aprofundada, assim como sua argumentação a favor da liberdade individual. Também, apresenta uma releitura das principais doutrinas do liberalismo clássico do século XIX e demonstra as diferentes maneiras de como a liberdade se expressa no Estado de bem-estar social, principal forma de organização política dos países ocidentais após a Segunda Guerra.

No ensaio Liberdade para o Progresso, Crespigny (1982) aponta que após a publicação do livro, Hayek sofreu críticas duras e irracionais, apontando-o como expoente do laissez-faire, autoritário e antidemocrático. Entretanto, não se encontra nada em sua obra que comprove essas assertivas, o que levanta questionamentos sobre como os críticos chegaram a tais conclusões. Para Merquior (1986), Hayek é o principal fator intelectual para o renascimento do debate sobre a importância da liberdade econômica, que havia sido abandonado na primeira metade do século XX.

As principais inspirações de Hayek remetem ao século XVIII e ao século XIX, sendo um grande admirador do liberalismo clássico, tecendo constantemente elogios a autores como Stuart Mill, Alexis de Tocqueville e Edmund Burke. Também, se inspirava nos escritos de Adam Ferguson e Adam Smith, ao pensar que "o progresso decorre das ações do homem, mas não do desígnio do homem" (MERQUIOR, 1991, p. 227).

Além dos liberais clássicos, Hayek também sofreu grande influência de dois economistas da Escola Austríaca: Carl Menger e Ludwig von Mises. Tal influência é crucial para compreender o pensamento de Hayek, visto que é considerado um dos maiores expoentes da Escola Austríaca no século XX, mesmo que tenha se afastado das concepções libertárias mais radicais presentes nessa tradição. Para De Vita (2011), o libertarianismo não se posiciona de maneira favorável a um rol extensivo de liberdades garantidos pelo Estado. Na verdade, ele defende um Estado com poucas obrigações morais que podem ser justificadas em nome da justiça. 
Na época em que Hayek obteve seu maior êxito acadêmico, Rawls já era observado e tinha seu trabalho acompanhado por diversos profissionais da filosofia. Embora, não possuísse reconhecimento internacional, suas ideias já eram, relativamente, conhecidas no ambiente acadêmico americano. Esse panorama sofreu uma drástica mudança com a publicação de seu livro Uma Teoria da Justiça, em 1971. De tamanho extenso e com uma proposta ambiciosa, o livro reunia elementos de inspiração kantiana e contratualista, e rapidamente se tornou o centro de debate acadêmico daquela década. A relevância da obra colocou Rawls como um dos principais expoentes do liberalismo igualitário, o qual é caracterizado pela recusa da mera liberdade negativa como garantia de direitos e pela necessidade de "arranjos institucionais básicos da sociedade, políticos e socioeconômicos" que permitam a cada cidadão "viver sua vida de acordo com suas próprias convicções de valor moral" (DE VITA, 2011, p. 574).

Nagel (2002, p. 63) discorre que Rawls foi responsável por elaborar uma síntese entre os princípios socialistas europeus com os princípios igualmente fortes de pluralidade e liberdade pessoal do liberalismo americano, nas palavras do autor:

In brief, what Rawls has done is to combine the very strong principles of social and economic equality associated with European socialism with the equally strong principles of pluralistic toleration and personal freedom associated with American liberalism, and he has done so in a theory that traces them to a common foundation. The result is closer in spirit to European social democracy than to any mainstream American political movement. ${ }^{1}$

O livro propõe uma espécie de releitura do contratualismo de tradição moderna: enquanto o contratualismo de Hobbes se baseia na segurança e o de Locke na defesa da propriedade, o contratualismo de Rawls propõe firmar regras de justiça (MERQUIOR, 1991).

Para além do contratualismo, a obra de Rawls também busca fornecer "uma fundamentação teórica para o conceito de justiça", contestando o utilitarismo predominante de Stuart Mill e Jeremy Bentham, segundo Gorowitz (1982, p. 268). Rawls (1971) classifica o utilitarismo como a postura que considera um ato como correto quando maximiza a felicidade geral. A sua proposta mostra-se como "cega", livre de preconceitos perante o conteúdo das diferentes solicitações em disputa, como também em relação aos específicos titulares desses desejos ou interesses, conforme aponta Gargarella (2001).

Ao contrário de Rawls que possui uma abordagem deontológica, na qual a importância moral do ato encontra-se em si mesma, Hayek defende uma concepção utilitária afastada daquela defendida pelos utilitaristas clássicos. Enquanto Mill e Bentham defendiam ações que buscassem maximizar a felicidade geral da sociedade, Hayek defende que as ações humanas devem maximizar o progresso da sociedade, caracterizando um "utilitarismo evolucionário" (GRAY, 1981).

De acordo com Rawls (1971), é possível que as pessoas aguentem sacrifícios na esfera individual, no entanto, isso se torna inaceitável na esfera social. Uma vez que é inconcebível

1 “Em suma, o que Rawls fez foi combinar os fortes princípios de igualdade econômica social e econômica associados ao socialismo europeu com os igualmente fortes princípios de tolerância pluralista associados ao liberalismo americano, e ele fez isso em uma teoria que os traçou a uma origem comum" [Tradução nossa]. 
a ideia de sacrificar desejos da geração atual para garantir benefícios a gerações futuras ou melhorar a vida dos demais. Em oposição, Hayek (1944, p. 72) defende privações de desejo no curto prazo para ter uma maior chance de progresso no futuro. De acordo com o autor:

Devemos sacrificar uma comodidade e conforto no curto prazo para preservarmos o progresso futuro. Isso não quer dizer que em todos os casos o sacrifício de algum acréscimo no nosso presente irá ser recompensado, mas a posição favorável à liberdade é justamente de que devemos reservar espaço para os progressos espontâneos e imprevisíveis.

Um ponto crucial para compreender a filosofia da liberdade de Rawls é compreender a sua ideia de posição original. Rawls (1971) propõe que indivíduos sejam escolhidos aleatoriamente para negociarem princípios de justiça que irão reger a sociedade em questão, ou seja, estarão vivendo sob a regência desses princípios no futuro. As pessoas escolhidas estariam cobertas por um "véu de ignorância", o que as impede de conhecer fatos particulares sobre si mesmos e sobre as pessoas em sua volta. Embora possuam um vasto conhecimento geral sobre as coisas - conhecem as leis básicas da economia, reconhecem a existência da escassez de recursos materiais e possuem noções gerais do que é necessário para o funcionamento da sociedade e do processo político - não sabem nada específico sobre a sua personalidade, não sabem qual é seu sexo, orientação sexual, cor, classe social e não possuem noção nem mesmo das suas capacidades biológicas. Segundo Welter (2010, p. 137-138),

[o] recurso de Rawls ao véu da ignorância é fundamental, pois ele garante a imparcialidade na medida em que encobre as partes contratantes, impedindo que saibam sua identidade particular. Além disso, o véu de ignorância procura garantir que as informações a que as partes têm acesso na posição original sejam relevantes e que sejam sempre as mesmas.

As pessoas colocadas nesta situação tendem a escolher dois princípios de justiça:

1) cada pessoa deve ter um direito igual ao mais abrangente sistema de liberdades básicas iguais que seja compatível com um sistema semelhante de liberdades para as outras;

2) as desigualdades sociais e econômicas devem ser ordenadas de tal modo que sejam ao mesmo tempo (a) consideradas como vantajosas para todos dentro dos limites do razoável, e (b) vinculadas a posições e cargos acessíveis a todos (RAWLS, 1971, p. 64).

É importante ressaltar que esses indivíduos não são altruístas, mas "seguiriam o princípio 'maximínimo' (the maximin principle): estando inteiramente incertos quanto às consequências de sua opção, normalmente minimizarão o perigo de serem prejudicados" (MERQUIOR, 1991, p. 246). As pessoas buscam maximizar o seu ganho pessoal, apesar disso, ao mesmo tempo levam em consideração que podem sair prejudicadas se escolherem princípios discriminatórios ${ }^{2}$.

\footnotetext{
${ }^{2}$ Gorowitz (1982) aponta algumas das críticas mais importantes dos críticos em relação ao Rawls. A primeira delas questiona que, caso a ideia da posição original seja um "mecanismo heurístico", não seria inteligente fazer análises factíveis sobre as escolhas feitas nessa situação. Outra objeção importante é sobre as conclusões que as partes tomariam na posição original: os críticos apontam que as pessoas na posição original poderiam tomar decisões mais arriscadas (e ao mesmo tempo discriminatórias) devido à possibilidade de se tornarem parte de uma elite privilegiada.
} 
Sobre os princípios de justiça, afirma Welter (2010, p. 140) que “[o] primeiro princípio garante que todos tenham liberdades básicas iguais, enquanto o segundo nos permite interpretar a diferença entre tratar os homens meramente como meios ou tratá-los como fins em si mesmos."

O individualismo é outro ponto crucial de divergência entre os fundamentos dos dois autores. Hayek (1944) considera o individualismo como uma cultura de tradição milenar. O individualismo a que esse autor se refere, não é meramente uma espécie de egoísmo, é uma recusa ao socialismo e a todas as outras formas de coletivismo, tendo como suas principais características o respeito pelo indivíduo como ser humano, a supremacia das suas preferências e opiniões na esfera individual e a convicção de que o indivíduo desenvolva virtudes e inclinações pessoais.

No entanto, segundo Nagel (2002), Rawls expõe uma clara oposição ao individualismo na medida em que propõe um sistema que busca reivindicar ao mesmo tempo a lealdade dos individualistas seculares e a lealdade daqueles de crença religiosa ortodoxa, mesmo que eles não compartilhem os mesmos valores determinantes da base de legitimidade do Estado. Nagel acredita que Rawls identificou uma fonte de convicção e motivação moral que não depende do ceticismo religioso ou de uma ética de autonomia individual.

\section{O conceito de liberdade para Rawls e Hayek}

Hayek inicia o livro O Caminho da Servidão abordando a crise na qual a Europa se encontrava na metade do século XX. Conforme Hayek (1944, p. 38), o totalitarismo que emergiu devido "a uma transformação do pensamento europeu que se acelerou mais entre alguns povos, levando-os a uma divergência irreconciliável com os nossos ideais", foi um dos principais responsáveis pela deturpação dos ideais que constituíram a base da sociedade europeia. Em especial pelo abandono da liberdade da ação econômica, a qual Hayek considera como condição de existência para as demais liberdades.

O primeiro conceito de liberdade elaborado por Hayek é deveras simples, com pouca sistematização e ligado fortemente ao livre mercado. Segundo Hayek (1944), a liberdade é exercida através do sistema de preços em um regime de concorrência. Tal sistema permite que um empresário ajuste sua atividade e seus preços de acordo com as circunstâncias e os gostos dos seus concidadãos, bem como permite que os clientes expressem a sua vontade ao comprar aquilo que lhe satisfaz por um preço que consideram justo, ou pelo menos, acessível. Ademais, a expressão da liberdade e a complexidade do sistema comercial não seriam atingidos em um regime de planejamento central consciente.

Hayek (1944) discorre que a doutrina liberal é favorável ao emprego efetivo das forças de concorrência como um meio de coordenação dos esforços humanos e busca empregar a melhor maneira de orientar os esforços individuais e permitir que o indivíduo expresse a sua vontade de maneira suprema. O economista argumenta que para o funcionamento eficaz de tal sistema, é necessária a existência de instituições como a moeda, os mercados, os canais de informação, um amplo sistema de serviços sociais e, principalmente, o reconhecimento da propriedade privada pelo sistema jurídico. 
Ao contrário de Hayek, Rawls (1971) não considera a propriedade privada como uma parte essencial do sistema de liberdades individuais, mas apenas como um dos pilares do sistema econômico responsável pelo investimento, produção e acumulação de capital na sociedade. Nagel (2002, p.68) afirma que o direito à propriedade na obra de Rawls "é a consequência, e não a fundação, da justiça das instituições econômicas" e que os libertários tendem a pensar isso de maneira contrária. Ainda nesse sentido, Muller afirma (2019, p. 55) que:

[...] para a teoria de justiça rawlsiana o foco principal não é assegurar a propriedade privada como um todo visto que, inclusive, é concebível que a sociedade igualitária de Rawls possua seu sistema econômico baseado nas regras do Socialismo. O que importa para o autor é que, independentemente das escolhas feitas no estágio legislativo da estruturação da sociedade, sejam respeitados os princípios de liberdade básica e que o princípio da diferença seja devidamente observado na (re)distribuição de recursos.

Além da defesa da liberdade em função de um sistema econômico livre, Hayek (1944) se opõe veementemente ao planejamento central e ao controle da economia. De um modo geral, os economistas não são contrários ao planejamento em sua concepção mais generalizada, que envolve a maneira como os homens planejam suas atividades e como eles deveriam planejálas. Contudo, o que os defensores do planejamento central exigem é:

um controle centralizado de toda a atividade econômica de acordo com um plano único, que estabeleça a maneira pela qual os recursos da sociedade sejam 'conscientemente dirigidos' a fim de servir, de uma forma definida, a finalidades determinadas. (HAYEK, 1944, p. 57)

Mesmo que o estado apenas controle diretamente uma grande parte dos recursos materiais disponíveis, os efeitos das suas decisões passam a causar tantos efeitos sobre as demais esferas da sociedade, que de forma indireta, esse passa a controlar quase tudo. Dessa maneira, serão poucos os objetivos individuais que não estarão à mercê do estado (HAYEK, 1944).

Na economia planificada, Hayek (1944) argumenta que a autoridade usaria seus poderes para auxiliar a consecução de certos fins e impedir a realização de outros. Nossos resultados não seriam determinados pela opinião que tivéssemos acerca do que devemos ou não preferir, mas pelas ideias de outra pessoa. A autoridade iria ditar diretamente a maneira de gastar nossos rendimentos. Hayek (1944), também, afirma que é uma conclusão errônea acreditar que "as mudanças de ordem econômica só afetam a periferia, a 'margem' das nossas necessidades", pois "ter as nossas atividades econômicas controladas significa ser controlados sempre, a menos que declaremos em cada caso nosso propósito específico".

Ao se passar essa competência para o Estado, o planejador decide o que é de maior ou menor importância para todos, e, assim, já não se consegue decidir o que se considera marginal.

Essa movimentação em direção a um número maior de regras e limitações pelo poder estatal vai contra tudo que a sociedade tem conquistado nos últimos séculos, segundo Hayek (1944, p. 76),

Desde o homem primitivo, restringido por um complicado ritual que abrangia todas as suas atividades cotidianas, limitados por inúmeros tabus, e que mal podia conceber uma conduta 
diferente da dos seus companheiros, a moral vem apresentando uma tendência a tornar-se cada vez mais uma simples linha divisória a circunscrever a esfera em que o indivíduo pode agir livremente. A adoção de um código comum de ética que seja abrangente a ponto de determinar um plano econômico unitário importaria numa total inversão dessa tendência

No livro The Constitution of Liberty, Hayek apresenta a liberdade de uma maneira mais elaborada, sistematizada e até mesmo independente, o que permite uma comparação mais clara com a filosofia igualitária de Rawls. Ainda que não abandone a importância da liberdade econômica, essa deixa de ser o centro de discussão e passa a ser a questão da coerção.

Já Rawls, no livro Teoria da Justiça, condiciona a liberdade ao princípio da igualdade e da justiça. A liberdade deve estar em consonância com a justiça como equidade, partindo da ideia que:

quando princípios comuns são necessários e trazem vantagens para todos, eles devem ser formulados a partir do ponto de vista de uma situação inicial de igualdade, adequadamente definida, na qual cada pessoa é representada de maneira equitativa. (RAWLS, 1971, p. 241)

Rawls (1971) discorre que o exercício pleno da liberdade só pode acontecer em um sistema que obedeça aos dois princípios da liberdade igual, citados anteriormente no texto. O primeiro princípio é o padrão primário para a convenção constituinte. As liberdades individuais fundamentais e a liberdade de pensamento e consciência devem ser protegidas e o processo político como um todo deve ser justo. O segundo princípio atua no campo da legislação ordinária. Ele determina que as políticas sociais e econômicas devem maximizar as expectativas dos menos favorecidos no longo prazo, garantindo uma igualdade equitativa de oportunidades e garantindo a manutenção das liberdades iguais. Rawls (1971) também reitera que o primeiro princípio possui prioridade em relação ao segundo, já que o primeiro está no campo do direito constitucional enquanto o segundo refere-se ao estágio legislativo.

Gorowitz (1982) expõe que o segundo princípio, dentro do cerceamento total da formação das instituições e práticas sociais, estabelecido pelo primeiro, constitui uma das únicas exceções em que Rawls permite a criação de desigualdade, desde que o seu propósito seja para beneficiar os menos favorecidos.

As liberdades para Rawls (1971) não podem ser desiguais, no sentido de que uma categoria de pessoas tenha uma maior do que a outra ou que a liberdade de uma minoria seja menos extensa do que deveria ser. Todavia, mesmo em um sistema de total liberdade básica, ainda pode existir uma diferença entre a liberdade e o valor da liberdade. A liberdade é representada pelo sistema completo de liberdades de cidadania igual, enquanto o valor da liberdade diz respeito à capacidade de exercer essa liberdade dentro da estrutura definida pelo sistema. Enquanto o sistema de liberdades deve levar em consideração o princípio da equidade no ordenamento jurídico, o valor da liberdade deve ser compensado na estrutura básica da sociedade, a qual deve ser ordenada para maximizar o valor para os menos favorecidos no sistema de liberdades iguais.

Com a finalidade de fazer uma classificação mais detalhada da liberdade para Hayek e Rawls, faz-se necessário utilizar a classificação de liberdade elaborada por Isaiah Berlin no 
ensaio Two Concepts of Liberty. Berlin (1959) entende a liberdade negativa como a ausência de coerção e a ausência de obstáculos para atingir um certo objetivo, ao passo que a liberdade positiva é o exercício da autonomia, é o desejo que o ser humano possui de ser o seu próprio mestre e guiar as suas decisões por preceitos racionais. Hayek (1960) defende que a verdadeira liberdade é a liberdade negativa, e afirma que a liberdade só se torna positiva através do seu uso. A liberdade real não assegura nenhuma oportunidade em particular, mas deixa decidir qual uso será feito a partir da circunstância que é apresentada.

Ao contrário de Hayek, Rawls (1971) não se preocupa em definir um conceito estrito de liberdade, a partir de conceitos como liberdade negativa ou positiva. Este não se preocupa com definições, mas com os valores relativos das várias liberdades quando conflitantes entre si. Entretanto, formula uma descrição geral da liberdade: esta ou aquela pessoa está livre daquela restrição (ou restrições) para fazer ou não fazer isto ou aquilo.

Para Hayek (1960, p. 57), o estado de liberdade é caracterizado como aquele em que “a coerção de uns sobre os outros é reduzido ao máximo na sociedade", sendo a coerção o controle de um ambiente ou circunstância de uma pessoa sobre outra, e para evitar o mal maior, a pessoa coagida é forçada a agir não segundo um plano coerente que ela própria elaborou, mas a fazer a vontade do outro. Embora em nenhum momento negue o valor intrínseco da liberdade, ele normalmente trabalha com um conceito de liberdade individual que é livre de valores na medida em que é inteligível e proveitoso para todos, independente da sua opinião sobre a natureza ou origem dos valores da liberdade (GRAY, 1991).

Rawls se aproxima de Hayek ao recusar o valor absoluto da liberdade, pois a suposta existência de um valor intrínseco da liberdade dificultaria a aplicação do sistema de liberdades básicas em contextos diferentes, conforme aponta Mendes (2009, p. 68):

[...] nenhuma liberdade tem um valor absoluto e as liberdades não mais devem ser dispostas num esquema mais abrangente possível, mas, sim, ajustar-se a um esquema plenamente adequado, de acordo inclusive com as distintas circunstâncias sociais que se vão revelando à medida que o véu da ignorância vai sendo retirado.

Outro ponto importante para entender a liberdade para Hayek é o conceito de coerção. Ele define a coerção como "o controle de um ambiente ou circunstância de uma pessoa sobre outra, e para evitar o mal maior, a pessoa coagida é forçada a agir não segundo um plano coerente que ela própria elaborou, mas a fazer a vontade do outro" (HAYEK, 1960, p. 71). Ainda de acordo com o autor, a coerção é má porque elimina o pensamento individual e o valor da pessoa e a transforma em uma mera ferramenta para atingir os fins de um terceiro. Para Sufrin:

[...] the ideological Enemy for Hayek is coercion. The imposition of constraint or the forcing of one's will upon another is evil. To be sure, restraint, voluntarily accepted as in the case of learning a trade or acquiring some special qualification, is not coercion in the sense Hayek uses it. (SUFRIN, 1960, p. 203) ${ }^{3}$

\footnotetext{
3 “o inimigo ideológico de Hayek é a coerção. A imposição de restrições ou a imposição da vontade de um sobre o outro é má. Certamente, a restrição voluntariamente aceita, como no caso de aprender um ofício ou adquirir alguma qualificação especial, não é coerção no sentido em que Hayek a usa" [Tradução nossa].
} 
E mais importante do que o conceito de liberdade em si, é rejeitar os diferentes conceitos de liberdade. As diferentes "liberdades" não são diferentes espécies do mesmo gênero, mas condições inteiramente diferentes, constantemente em conflito uma com as outras. A liberdade em si mesma deve variar em grau, mas nunca em tipo. Devemos diferenciar a verdadeira liberdade, a ausência da coerção, das liberdades falsas que enganam e distorcem o significado da palavra (HAYEK, 1960).

A primeira liberdade que Hayek (1960) distingue é a liberdade política, caracterizada pela participação do homem na escolha do seu governante, do processo legislativo e do controle administrativo. Essa não pode ser uma liberdade pois somos inseridos em uma ordem social que utiliza a política desde que somos pequenos, é apenas uma instituição funcional da sociedade, não uma manifestação da liberdade. Além disso, é uma escolha feita de maneira coletiva, enquanto a liberdade em si é exercida na esfera pessoal do indivíduo.

Tal distinção demonstra uma divergência com o pensamento de Rawls (1993) acerca da liberdade política, o qual a considera tão importante que a inclui no rol de liberdades fundamentais do seu sistema de liberdades. Mesmo que o papel das liberdades políticas seja instrumental (normalmente ela serve para a preservação das outras liberdades), isso não constitui um impedimento para colocar certas liberdades políticas entre as liberdades básicas e protegê-las com a prioridade da liberdade (RAWLS, 1993). A liberdade política é necessária para satisfazer o princípio da participação, o qual é condição para o funcionamento de um sistema político justo e eficaz (MENDES, 2009).

A segunda liberdade que Hayek (1960) faz a distinção é a liberdade interior ou metafísica. Ela é caracterizada pelo uso da razão, da vontade própria ou de uma convicção duradoura para controlar impulsos e emoções circunstanciais. Ainda que ela seja uma resistência contra impulsos, é uma resistência contra impulsos internos, e não sobre forças externas - pessoas ou instituições impondo a vontade delas sobre alguém - agindo sobre a pessoa, diferenciando-se assim da liberdade em si.

A terceira liberdade é o uso da liberdade como forma de exercer a sua vontade sem restrições, é a liberdade como poder para satisfazer os seus desejos. Essa liberdade se difere da liberdade real pois é uma expressão positiva, é a vontade de fazer algo, enquanto a primeira é uma liberdade negativa, caracterizada pela ausência de restrições e constrangimento (HAYEK, 1960).

Para finalizar o raciocínio sobre a pluralidade de liberdades, Hayek (1960, p. 70) afirma:

But while the uses of liberty are many, liberty is one. Liberties appear only when liberty is lacking: they are the special privileges and exemptions that groups and individuals may acquire while the rest are more or less unfree. Historically, the path to liberty has led through the achievement of particular liberties. But that one should be allowed to do specific things is not liberty, though it may be called "a liberty"; and while liberty is compatible with not being allowed to do specific things, it does not exist if one needs permission for most of what one can do. The difference between liberty and liberties is that which exists 
between a condition in which all is permitted that is not prohibited by general rules and one in which all is prohibited that is not explicitly permitted. ${ }^{4}$

Crespigny (1982, p. 58) esclarece que a rejeição de Hayek ao sentido comum de liberdade:

Pode ser parcialmente explicada pelo seu desejo de preservar "o sentido original da palavra", e de acentuar sua utilidade ao restringir rigorosamente sua aplicação. O que é importante é a sua determinação de que o valor cardinal da liberdade não deveria ser explorado pelos coletivistas para justificar grande parte das intervenções estatais.

Por meio desse pensamento, percebe-se outra divergência em relação ao pensamento dos dois filósofos, visto que Rawls aceita e promove a existência de uma pluralidade de liberdades por meio de um sistema total de liberdades básicas elaborado pela "preferência racional das partes situadas na posição original" (MENDES, 2009, p. 51), enquanto Hayek defende a existência de uma única liberdade.

Uma liberdade fundamental só pode ser limitada ou negada em nome de outra liberdade fundamental - nunca por razões de bem-estar geral ou de valores perfeccionistas. Rawls (1971) frisa que liberdades não são absolutas, pois podem entrar em choque entre si, e não é absoluta a exigência de que todas devem ser igualmente oferecidas. $\mathrm{O}$ americano também discorre sobre a limitação das liberdades, afirmando que a liberdade de pensamento, de consciência, a liberdade individual e as liberdades civis não devem ser sacrificadas em nome da liberdade política, da liberdade de participar igualmente nos assuntos políticos.

Ainda que seja favorável a um sistema plural de liberdades, Rawls (1993) se posiciona contra o aumento da lista de liberdades fundamentais já delimitadas em sua teoria, porque, em sua concepção, ao ampliar a lista, corre-se o risco de enfraquecer a proteção das liberdades mais essenciais e de recriar no interior do sistema de liberdades os problemas de indeterminação e desorientação que se tinha a esperança de evitar com o conceito de prioridade previamente descrito.

\section{Análise de conceitos adjacentes à liberdade}

Como citado anteriormente, Hayek foi um grande estudioso do liberalismo clássico e por muitos anos dedicou seus estudos à importância da prudência, da liberdade e da estabilidade das instituições. Entretanto, aponta Gray (1981) que quando Hayek passou a se dedicar exclusivamente ao estudo da filosofia política, passou a discordar das teorias utilitárias clássicas: as ações tomadas pelo homem não devem visar a felicidade ou o bem estar da

\footnotetext{
${ }^{4}$ Enquanto os usos da liberdade são muitos, a liberdade é uma só. Liberdades aparecem quando a liberdade está em falta: elas são privilégios e isenções especiais que grupos e indivíduos podem adquirir, enquanto o resto é mais ou menos não livre. Historicamente, o caminho para a liberdade conduziu à conquista de certas liberdades. Mas ter permissão para fazer coisas específicas não é liberdade, embora talvez seja chamada de "uma liberdade"; e enquanto liberdade seja compatível com a proibição de fazer certas coisas, ela não existe se o indivíduo necessita de permissão para fazer a maioria das coisas que está apto a fazer. A diferença entre liberdade e liberdades é a mesma que existe entre uma condição na qual é permitido tudo o que não seja proibido por normas gerais e outra, na qual é proibido tudo que não seja explicitamente permitido. [Tradução nossa]
} 
população, mas sim o progresso e o avanço da civilização. Logo, a liberdade para Hayek não é um valor em si mesmo, é uma ferramenta social para auxiliar no progresso da sociedade e o objetivo principal de todo ser humano é contribuir, ainda que involuntariamente, para a evolução social (MERQUIOR, 1991).

Seguindo essa linha de pensamento, Hayek assumiu um pensamento evolucionista, argumentando que, embora o homem tenha criado a civilização ao longo de centenas e centenas de gerações, isso não significa que a civilização é resultado do planejamento humano, nem mesmo que o homem sabe do que ela necessita para seu funcionamento ou existência contínua. O progresso é um processo de formação e modificação do intelecto humano, um processo de adaptação e aprendizagem no qual não apenas as possibilidades conhecidas, mas também os valores e desejos estão em constante mudança. Como o progresso consiste na descoberta do desconhecido, suas consequências não podem ser previstas. A tentativa de fazer a ciência visar deliberadamente a um conhecimento útil - isso é, um conhecimento que os usos futuros podem ser previstos - é possível que impeça o progresso. O progresso pela sua própria natureza não pode ser previsto ${ }^{5}$ (HAYEK, 1960).

Merquior (1991, p. 228) descreve que Hayek "colocou o kósmos, ou ordem criativa espontânea, como sendo muito superior a táxis, ou ordem feita, exógena - o arranjo intencional das utopias racionalistas". Ainda nesse sentido, complementa Espada (1995, p. 278),

Dado que a obra inicial de Hayek foi essencialmente normativa, e dado que ele foi gradualmente evoluindo para uma postura evolucionista, o resultado é que ele é conduzido à posição singular de alguém que sabe que a moral que escolheu em bases normativas é também aquela que será necessariamente selecionada pela evolução natural.

Segundo Lister (2011), Hayek não está preocupado com a origem espontânea das regras em si, mas com o caráter espontâneo da ordem que permite os indivíduos alcançarem seus próprios objetivos. A crença no progresso, através de uma seleção natural de instituições, resulta na ideia de "ordem espontânea" defendida pelo economista:

Hayek's idea of spontaneity refers both to the origin of the rules that first give rise to order, and to the character of an order even after the rules have been modified by intentional acts of legislation. Human societies are normative or rule-governed arrangements that were initially the product of evolution rather than conscious design. We didn't start out as the individually rational consequentialists of economic theory, but as herd animals that very slowly developed complicated social norms and eventually explicit rules. Human societies were subject to selection pressures. If a particular rule tended to disrupt group life, or weaken the group in competition with others, that rule would tend to be weeded out of

\footnotetext{
${ }^{5}$ Merquior (1991) aponta o raciocínio evolucionista de Hayek como uma das maiores falhas de todo o seu pensamento: se as instituições possuem uma espécie de sabedoria inerente Hayek não deveria recusar instituições como o controle de renda e a taxação progressiva, visto que elas são o resultado de evoluções imprevistas. Espada $(1995$, p. 280) também crítica tal pensamento de Hayek afirmando que mesmo que as instituições defendidas pelos evolucionistas tenham surgido de maneira espontânea e sem planejamento, elas ainda necessitam de uma constante manutenção feita pelo caráter racional do ser humano.
} 
the population of human societies. If a particular rule promoted cohesion and strength, it would tend to be selected. (LISTER, 2011, p. 8) ${ }^{6}$

Rawls, estando inserido na tradição racionalista do liberalismo, considera as decisões racionais com objetivos pré-estabelecidos como essenciais para o progresso da civilização. Isso é observado com clareza na decisão dos indivíduos presentes na posição original, que tendem a fazer as escolhas mais racionais possíveis, e consequentemente, contribuem para a possibilidade de uma sociedade melhor e mais justa.

O ponto de partida da teoria política do liberalismo igualitário de Rawls não é uma concepção de liberdade, muito menos de liberdade negativa e, sim, uma noção de igualdade. Uma sociedade justa é uma ordem social e política, cujas instituições principais garantem a todos os cidadãos certas condições que podemos denominar igualdade humana fundamental ou igualdade moral. A igualdade de condições é assegurada quando os arranjos institucionais básicos de uma sociedade - sua estrutura básica - devotam a seus cidadãos, independentemente de quanto dinheiro ou riqueza cada um possua ou de seus talentos e capacidade produtiva, um tratamento igual que só é possível àqueles que são portadores de direitos iguais. Em uma sociedade justa, a distribuição das vantagens e dos ônus da cooperação social se faz levandose em conta e de modo a garantir esse status social e moral igual (DE VITA, 2011).

Ao contrário de Rawls, Hayek (1960) discorre que a igualdade das regras jurídicas e de conduta são os únicos tipos de liberdade que podemos assegurar sem destruir a liberdade. Não só a liberdade não tem nada a ver com nenhum outro tipo de igualdade, como na verdade ela pode produzir desigualdades em vários aspectos. Entretanto, as forças que em primeiro momento fazem a desigualdade se acentuar, fazem com que essa própria desigualdade diminua tempos depois.

Outro princípio importante que Rawls leva em consideração, é o princípio do mérito. $\mathrm{O}$ filósofo considera que os indivíduos não deveriam poder aproveitar as vantagens derivadas de renda, afiliações e outros privilégios, assim como não deveriam receber nenhuma vantagem da "loteria natural", como inteligência, força, entre outros. Os resultados desiguais oriundos dessas vantagens só deveriam ser aceitos caso beneficiem os mais necessitados (MICHELBACH; BORNSTEIN, 2003).

Hayek (1960) se posiciona de forma contrária a Rawls quase que de maneira integral: vê pouco valor na valorização do mérito e reconhece diversas qualidades proporcionadas pela "loteria natural". A respeito do mérito, Hayek argumenta que o valor que as habilidades e serviços de uma pessoa tem a oferecer pouco tem a ver com o que podemos chamar de mérito

\footnotetext{
${ }^{6} \mathrm{~A}$ ideia de Hayek de espontaneidade se refere tanto a origem das regras que primeiro dão origem à ordem, quanto ao caráter de uma ordem, mesmo depois de as regras terem sido modificadas por atos legislativos intencionais. As sociedades humanas são arranjos normativos ou governados por regras que foram inicialmente o produto da evolução ao invés de um planejamento consciente. Não começamos como os indivíduos racionais consequencialistas da teoria econômica, mas como animais de rebanho que, muito lentamente, desenvolveram normas sociais complicadas e, por fim, regras explícitas. As sociedades humanas estavam sujeitas à processos de seleção. Se uma regra particular tende a perturbar a vida em grupo, ou enfraquecer o grupo em competição com outros, a regra tende a ser eliminada da população das sociedades humanas. Se uma regra promove coesão e força, ela tende a ser selecionada. [Tradução nossa]
} 
moral. Lister (2011) demonstra que, para Hayek, o funcionamento de um sistema econômico que tire o máximo de proveito da distribuição do conhecimento na sociedade não irá recompensar o indivíduo pelo seu esforço subjetivo (dor, esforço, tempo gasto), mas sim pelo resultado efetivo das ações tomadas pelos indivíduos, ainda que essas sejam acidentais. Não se deve desejar que as pessoas conquistem o máximo de mérito, mas que elas alcancem o máximo de utilidade com o mínimo de dor e sacrifício, consequentemente com o mínimo de mérito.

Na questão da "loteria natural", Hayek considera a variedade sem limites um dos fatos mais únicos acerca da natureza humana, a evolução natural tornou os seres humanos a criatura com mais distinções dentre sua própria espécie do que qualquer outra.

Um dos únicos pontos em que a opinião dos dois autores converge é no reconhecimento da importância do estado de direito para garantir a soberania do indivíduo e a defesa da lei geral e abstrata.

Rawls (1971) pontua que o Estado de Direito é responsável pela proteção e garantia das liberdades da pessoa. Ele está diretamente relacionado com os princípios de justiça, que garantem que o Estado não violará os direitos de cada cidadão. As decisões judiciais devem ser padronizadas, ou seja, os juízes devem adotar os mesmos critérios para a decisão de casos semelhantes, evitando assim a possibilidade do abuso de poder por parte do judiciário.

O que difere um país livre de um país submetido a um governo arbitrário é a existência do estado de Direito. Isso significa que todas as ações do governo são regidas por normas previamente estabelecidas e divulgadas, o que permite saber previamente a forma como o Estado fará o uso da coerção, permitindo a cada um planejar suas atividades individuais a partir disso. E para que o estado de Direito exista, é necessário que haja normas aplicadas sem exceções, essas devem ser aplicadas da mesma forma em todos os casos - mesmo que numa situação particular ela seja considerada injusta (HAYEK, 1944).

\section{Conclusão}

Embora, comumente, se pense o liberalismo como uma ideologia padronizada, percebese que as suas diferentes correntes ideológicas podem apresentar mais divergências entre si do que o esperado, principalmente quando se analisa a origem ideológica do pensamento de cada autor.

As inspirações de Rawls remetem ao liberalismo racionalista, representado por autores como Jean-Jacques Rousseau, Immanuel Kant e Thomas Paine. A vertente racionalista defende que a fundação da civilização ocorreu de forma racional e deliberada, foi uma escolha dos humanos que quiseram elevar a condição da sociedade. Não há instituições que não surgiram a partir da razão e da deliberação humana. Além disso, enxerga o ser humano como naturalmente bom e inteligente, guiado pelas ações racionais. Isso se torna presente na obra de Rawls quando esse defende que os indivíduos escolheriam os princípios de justiça quando estivessem atrás do "véu da ignorância".

Diferentemente de Rawls, as inspirações de Hayek derivam do liberalismo tradicional, representado por autores como John Locke, Adam Smith e Alexis de Tocqueville. Os liberais 
clássicos acreditam que a civilização se origina dos resultados de tentativa e erro, sendo uma parte dessa experiência herdada de geração em geração como conhecimento explícito, e a outra parte como ferramentas e instituições que se provaram superiores ao longo dos anos. Tais autores argumentam que o valor da liberdade consiste na oportunidade de crescimento do não planejado e o funcionamento da sociedade depende em grande parte da existência de tais instituições criadas livremente. Isso se torna presente na obra de Hayek, uma vez que esse defende explicitamente o papel da imprevisibilidade no progresso, assim como a liberdade de consciência ilimitada.

Também é possível notar diferenças claras no conceito estrito de liberdade. Hayek defende uma liberdade negativa, caracterizada pela ausência de coerção e importância do livre mercado, ao passo que Rawls defende a liberdade em função da justiça e da igualdade. A questão da pluralidade das liberdades também é de extrema importância para compreender a divergência entre os dois autores: Rawls elabora um sistema de liberdades que deve ser respeitado hierarquicamente para o funcionamento da democracia, em contrapartida, Hayek recusa os conceitos plurais de liberdade, afirmando que a liberdade é uma só e não deve ser confundida com falsos conceitos.

Ainda que os autores concordem em diversos pontos sobre a estrutura do Estado, como a defesa da democracia como o meio mais eficiente de garantir a liberdade, a defesa da norma geral e da previsibilidade da coerção pelo Estado e do Estado de Direito como meio de evitar autocracias, os dois autores apresentam mais divergências do que similaridades. É até mesmo possível inferir que o liberalismo igualitário de Rawls se encontra mais próximo da democracia deliberativa e do socialismo democrático, e que o liberalismo individualista de Hayek se encontra mais próximo do libertarianismo.

\section{Referências}

BERLIN, Isaiah. Incorporating Four Essays on Liberty. Oxford: Oxford University Press, 1958.

CRESPIGNY, Anthony de. F. A. Hayek: Liberdade para o Progresso. In: Filosofia Política Contemporânea. Brasília: Editora da Universidade de Brasília, 1982.

DE VITA, Álvaro. Liberalismo, Justiça Social e Responsabilidade Individual. Revista de Ciências Sociais, Rio de Janeiro, v. 54, ed. 4, p. 569-608, 2011.

ESPADA, João Carlos. Direitos sociais e cidadania - uma crítica a F. A. Hayek e R. Plant. Análise Social, Lisboa, v. 30, p. 265-287, 1995.

GARGARELLA, Roberto. Teorias da justiça depois de Rawls. São Paulo: Martins Fontes. 2001.

GOROWITZ, Samuel. John Rawls: Uma teoria da Justiça. In: Filosofia Política Contemporânea. Brasília: Editora da Universidade de Brasília, 1982.

GRAY, John. Hayek on Liberty, Rights, and Justice. Ethics, Chicago, v. 92, n. 1, p. 73-84, 1981. Disponível em: www.jstor.org/stable/2380705. Acesso em: 10 jan 2021.

GRAY, John. F.A. Hayek on Liberty and Tradition. The Journal of Libertarian Studies, [s. l.], v. 4, ed. 2, p. 119137, 1980. 
HAYEK, Friedrich. O Caminho da Servidão. São Paulo: Instituto Ludwig von Mises Brasil, 2010.

HAYEK, Friedrich. The Constitution of Liberty. Chicago: The University of Chicago Press, 2011.

LISTER, Andrew. The 'Mirage' of Social Justice: Hayek Against (and For) Rawls. CSSJ Working Papers Series, Oxford, v. SJ017, p. 1-30, 2011. Disponível em: https://www.politics.ox.ac.uk/materials/centres/social-justice/ working-papers/SJ017_Lister_MirageofSocialJustice.pdf. Acesso em: 12 mar 2021.

MENDES, Lucas. Liberdade e bens primários: uma investigação da teoria de John Rawls a partir do Liberalismo Clássico. Dissertação, Mestrado em Filosofia. Universidade Federal de Santa Maria, Santa Maria, 2009. Disponível em: https://repositorio.ufsm.br/handle/1/9064. Acesso em: 15 fev 2021.

MERQUIOR, José Guilherme. Algumas Reflexões sobre os Liberalismos Contemporâneos. Rio de Janeiro: Instituto Liberal, 1991.

MERQUIOR, José Guilherme. O Liberalismo: Antigo e Moderno. Rio de Janeiro: É realizações, 2014.

MICHELBACH, P. et al. Doing Rawls Justice: An Experimental Study of Income Distribution Norms. American Journal of Political Science, Nebraska, v. 47, n. 3, p. 523-539, 2003.

MÜLLER, Rafael. LIBERDADE E JUSTIÇA EM JOHN RAWLS E ROBERT NOZICK. Dissertação, Mestrado em Filosofia, 2009. Universidade de Caxias Do Sul, Caxias do Sul, 2009. Disponível em: https://repositorio.ucs. br/xmlui/handle/11338/6244?locale-attribute=de. Acesso em: 15 fev 2021.

NAGEL, Thomas. Rawls and Liberalism. In: Cambridge Companion to Rawls. New York: Cambridge University Press, 2002.

RAWLS, John. Uma Teoria da Justiça. São Paulo: Martins Fontes, 2000.

RAWLS, John. O liberalismo político. São Paulo: Martins Fontes, 2011.

SUFRIN, Sydney C. Some Reflections on Hayek's The Constitution of Liberty. Ethics, Chicago, v. 71, n. 3, p. 201-204, 1961.

WELTER, Nelsi K. Vida, Liberdade e Propriedade: Rawls e Kant a partir da perspectiva de Paul Guyer. Ethic@, Florianópolis, v. 9, ed. 3, p. 133-153, 2010.

RECEBIDO EM: 19 DE MARÇO DE 2021.

APROVADO EM: 18 DE ABRIL DE 2021. 